\title{
4. Subjetificação, objetificação e (des) gramaticalização nas construções completivas infinitivas em português, em comparação com outras línguas românicas
}

Augusto Soares da Silva

Universidade Católica Portuguesa - Braga

\section{Introdução}

A alternância e a distribuição das construções subordinadas infinitivas e finitas são geralmente motivadas por fatores conceptuais: as diferentes construções de infinitivo não flexionado, infinitivo flexionado e finita em português contrastam não só em grau de integração estrutural dos eventos principal e subordinado, mas também em perspetivação conceptual ou, nos termos da Gramática Cognitiva de Langacker (I987, I99I, 2008), arranjo de visão nas posições do sujeito e objeto de per/conceção. Do ponto de vista do objeto de per/conceção, a construção de infinitivo não flexionado representa o grau mínimo e a construção finita o grau máximo de objetificação do evento subordinado. Do ponto de vista do sujeito de per/conceção (o locutor), a construção de infinitivo não flexionado representa o grau mínimo e a construção finita o grau máximo de subjetificação ou envolvimento do locutor na conceptualização do evento descrito.

Neste estudo, analisaremos sincrónica e diacronicamente o grau de subjetividade/objetividade e o grau de gramaticalização das construções completivas infinitivas de verbos percetivos, causativos, de controlo (como querer) e de elevação (como os verbos modais) em português, em comparação com outras línguas românicas. No português antigo, estes verbos eram mais afins dos verbos auxiliares. Do português antigo ao português moderno, verifica-se um incremento da construção bioracional com a introdução de propriedades estruturais que aumentam a independência do evento subordinado. Esta desgramaticalização,

Como citar este capítulo:

da Silva, Augusto Soares, Subjetificação, objetificação e (des)gramaticalização nas construções completivas infinitivas em português, em comparação com outras línguas românicas. In: Engwall, Gunnel \& Fant, Lars (eds.) Festival Romanistica. Contribuciones lingüísticas - Contributions linguistiques - Contributi linguistici - Contribuições linguísticas. Stockholm Studies in Romance Languages. Stockholm: Stockholm University Press. 20I 5, pp. 64-9I. DOI: http://dx.doi.org/IO.I6993/bac.d. License: CC-BY 
que se atesta também no espanhol, embora em grau menos acentuado, coloca o português num estádio mais recuado de gramaticalização das construções infinitivas em comparação com outras línguas românicas, como o francês e o italiano. Com base numa análise de corpus, descreveremos a desgramaticalização diacrónica que se verifica em português e no espanhol como um processo de objetificação do evento subordinado, particularmente do seu sujeito.

O presente texto está estruturado em oito pontos. A seguir a esta introdução, são apresentados breves apontamentos sobre gramaticalização, subjetificação e a natureza do infinitivo. Nos pontos três e quatro, são analisadas as diferenças conceptuais entre as construções infinitivas e finitas alternantes e é caracterizado o significado do infinitivo flexionado em português. Seguidamente, no ponto cinco, desenvolvemos uma abordagem conceptual das três construções infinitivas dos verbos causativos e percetivos e comparamos o seu grau de gramaticalização no português, espanhol, francês e italiano. No ponto 6 , analisamos a dupla tendência evolutiva das construções completivas infinitivas nas línguas românicas: o processo de gramaticalização no italiano e no francês e, em certos contextos, no espanhol e no português e o processo de desgramaticalização no espanhol e, mais rápida e nitidamente, no português. Segue-se, no ponto sete, uma explicação cognitiva destes processos de (des)gramaticalização com base nos processos conceptuais de subjetificação e objetificação. Finalmente, apresentamos as conclusões do presente estudo e sugestões para investigação futura.

\section{Gramaticalização, subjetificação e infinitivo}

O processo gradual de gramaticalização, pelo qual uma unidade lexical adquire uma função gramatical ou uma unidade gramatical adquire uma função ainda mais gramatical (Hopper \& Traugott 2003), manifesta-se em dois níveis: a nível do significado da unidade lexical/ gramatical, como um processo de debilitamento semântico, e a nível da construção, como um processo de integração estrutural de eventos. Isto significa que, entre as diferentes construções completivas, a mais gramaticalizada será aquela que apresentar um grau maior de debilitamento semântico do verbo principal e/ou de integração estrutural dos eventos subordinado e principal. Esta distinção está em sintonia com a assunção de que o processo de gramaticalização ocorre dentro de construções particulares (Bybee 2003; Traugott 2003, 2008). 
Menor variabilidade formal e semântica é sinal de alto grau de gramaticalização. A avaliação de um processo de gramaticalização envolve tanto a dimensão da saliência semasiológica (ou prototipicidade) como a dimensão da saliência onomasiológica (ou familiarização e convencionalização), tanto a dimensão lexical como a dimensão construcional e tanto a dimensão diacrónica como a dimensão sincrónica.

$\mathrm{Na}$ teoria linguística atual, existem duas abordagens principais do fenómeno da subjetificação, nomeadamente a abordagem funcionalista de Traugott (1989, I995), no quadro da Linguística Funcional, e a abordagem cognitivista de Langacker (I990, I999), no enquadramento da Linguística Cognitiva. Traugott focaliza o processo diacrónico e a dimensão pragmática da subjetificação, entendendo este fenómeno como um processo de mudança semântica pelo qual significados que descrevem uma situação externa passam a indicar perspetivas, atitudes e crenças do locutor em relação a essa situação. Langacker focaliza o próprio processo de conceptualização envolvido e entende a subjetificação em termos da dimensão conceptual da perspetiva ou arranjo de visão na relação assimétrica entre sujeito observador/conceptualizador e objeto observado/conceptualizado. Uma entidade ou situação é objetivamente construída na medida em que é colocada "dentro de cena" e vista do exterior, como foco específico de atenção, como objeto de per/ conceção; é subjetivamente construída na medida em que permanece "fora de cena", como sujeito não consciente de si mesmo e implícito de per/conceção. A subjetificação é, então, o processo pelo qual uma entidade passa de 'objeto' a 'sujeito' de per/conceção e, consequentemente, o conceptualizador/locutor (ou um outro elemento do ato de fala) deixa de ser um observador/elemento externo e passa a fazer parte do conteúdo de conceptualização.

Traugott assume uma perspetiva pragmático-funcional e explica a subjetificação em termos de reforço pragmático e como resultado da convencionalização de inferências contextualmente sugeridas. Em contrapartida, Langacker assume uma perspetiva cognitiva e explica a subjetificação em termos de perspetivação conceptual e como resultado de um processo de atenuação semântica. Apesar destas diferenças, que têm mais a ver com a conceção geral de linguagem, as duas abordagens são compatíveis e até se complementam, na medida em que reforço pragmático e atenuação semântica são duas dimensões de um mesmo fenómeno (ver Soares da Silva 20ı ia).

O infinitivo caracteriza-se pela sua natureza híbrida entre verbo e nome (ver Cristofaro 2007; Soares da Silva 2008; Vanderschueren 
2013): o infinitivo conceptualiza um evento, mas carece de certas características dos verbos e manifesta certas características dos nomes. Morfossintaticamente, carece de certas marcas tipicamente verbais, como o sufixo temporal, e ocorre apenas em contextos sintaticamente subordinados. Discursivamente, não assevera a atual ocorrência de um evento e não estabelece relação deítica com a realidade discursiva. Conceptualmente, e seguindo a caracterização cognitiva de Langacker (1987; I99I) relativamente às classes do verbo e do nome, o infinitivo conceptualiza um evento, não sequencialmente como um verbo, mas sumariamente (holisticamente) como um nome. Mais especificamente, o infinitivo implica um escaneamento mental sumário e concebe o processo na sua totalidade e sem focalizar a sua evolução no tempo.

Dada esta natureza híbrida, o infinitivo pode aproximar-se ou afastar-se mais ou menos do protótipo verbal. Por exemplo, desviam-se bastante do protótipo verbal os chamados infinitivos nominais, isto é, os infinitivos precedidos de determinante e que podem ser modificados por adjetivos. Já os infinitivos que regem complementos verbais ou que formam parte de uma perífrase ou ainda que constituem o núcleo de uma oração adverbial aproximam-se bastante do protótipo verbal. Neste contínuo de maior ou menor verbalidade do infinitivo, o português apresenta uma categoria ausente noutras línguas: é o infinitivo flexionado, que possui obviamente mais características verbais do que o infinitivo não flexionado. Veremos, na próxima secção, o contraste entre as duas formas de infinitivo, bem como o significado do infinitivo flexionado. Veremos, também aí, esse contraste em termos de gramaticalização e subjetificação.

\section{Construções infinitivas e finitas alternantes: diferenças conceptuais}

Os exemplos (a), (b) e (c) de (I)-(3) - que representam, respetivamente, a construção com infinitivo não flexionado (Inf NF) (a), a construção com infinitivo flexionado (Inf Fl) (b) e a construção com verbo finito (c) - constituem três modos diferentes de conceber uma mesma situação extralinguística. As diferenças entre as três construções - completivas em (I)-(2) e adverbiais em (3) - são essencialmente conceptuais e as três construções alternantes dispõem-se em diversas escalas conceptuais contínuas que têm a construção finita de um lado, a construção de Inf NF do outro e a construção de Inf Fl numa posição intermédia. 
O Quadro I identifica sete parâmetros conceptuais (em maiúsculas) que distinguem as três construções alternantes.

(I) a. É preciso fazer uma pausa.

b. É preciso fazermos uma pausa.

c. É necessário que façamos uma pausa.

(2) a. Eles reconheceram ter errado.

b. Eles reconheceram terem errado.

c. Eles reconheceram que erraram.

(3) a. Alegram-se por ver o pai.

b. Alegram-se por verem o pai.

c. Alegram-se porque veem o pai.

Vejamos brevemente as diferenças conceptuais que distinguem as três construções: ${ }^{\mathrm{I}}$

(i) independência do evento subordinado relativamente ao evento principal. A construção com Inf Fl codifica maior independência conceptual e menor integração dos eventos principal e subordinado do que a construção com Inf NF. Por isso, o Inf Fl tem várias marcas de um verbo independente: as marcas de pessoa e número e a marca nominativa do seu sujeito gramatical e, no caso das construções com verbos modais e verbos causativos e percetivos, preservação da estrutura argumental, não havendo pois subida de clíticos nem de argumentos.

(ii) especificidade do evento subordinado. Como vimos anteriormente, o infinitivo implica um escaneamento mental sumário, porque representa um processo tipo. No entanto, o Inf Fl é mais específico do que o Inf NF, pois explicita a referência pessoal, sendo pois mais concreto do que um processo tipo.

(iii) atualização ("grounding": Langacker I987, I99I) ou relação explícita com o ato de fala. O verbo finito estabelece uma relação epistémica com a situação enunciativa, isto é, situa o evento em relação à realidade, através das suas especificações de tempo, modo e seus participantes. A ele se opõe o infinitivo, que não implica tal atualização. Entre os dois encontra-se o Inf $\mathrm{Fl}$, que estabelece explicitamente a relação entre o participante principal do evento subordinado e os participantes do ato de fala, mas sem dar informação sobre o estatuto epistémico do respetivo evento.

(iv) proeminência da forma: o Inf Fl é, por um lado, mais proeminente do que o Inf NF, porque explicita mais informação acerca do evento subordinado, designadamente sobre o seu sujeito, e, por outro 


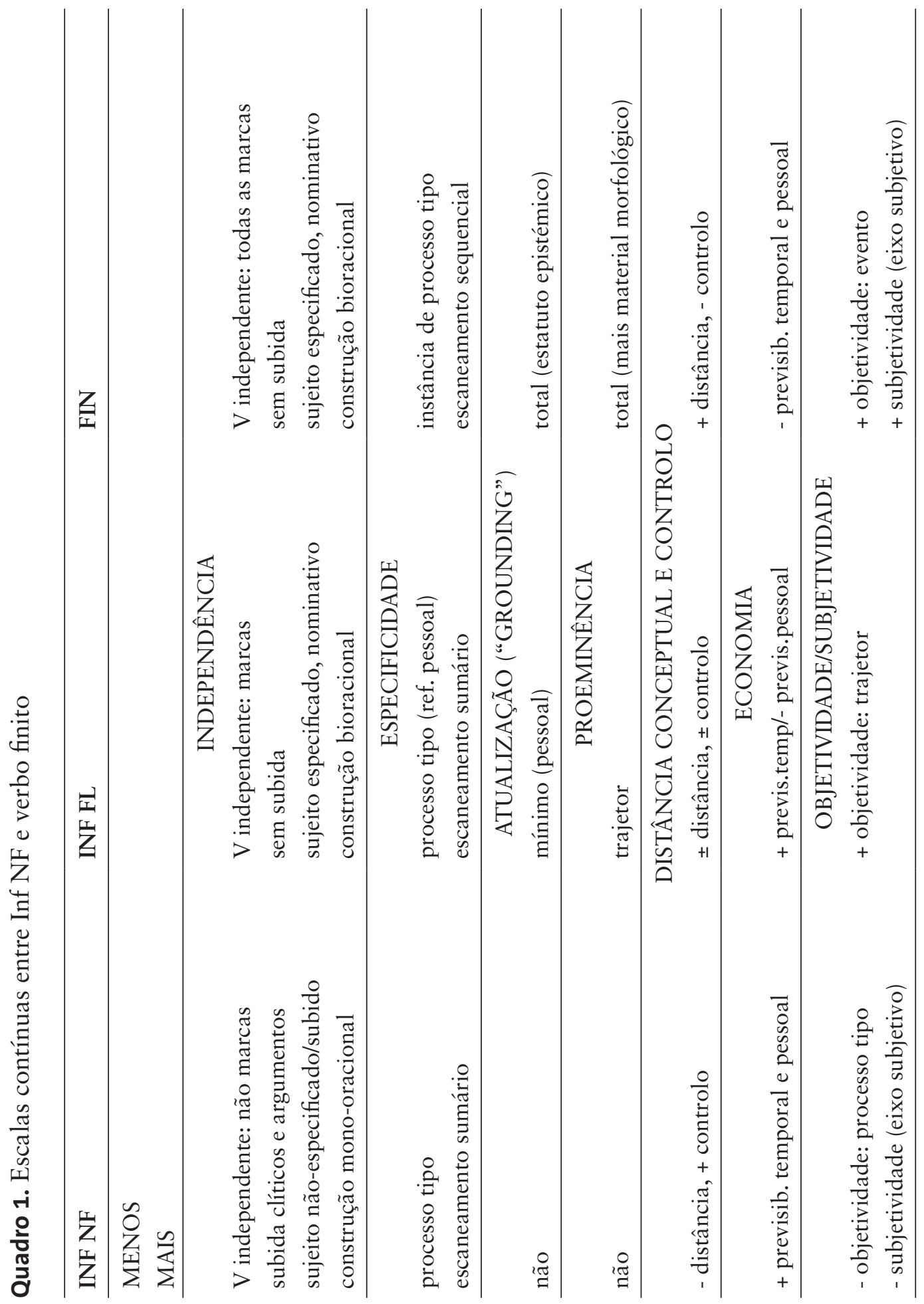


lado, menos proeminente do que o verbo finito, já que este contém mais material morfológico.

(v) distância conceptual e controlo. Seguindo Haiman (I 980) e Givón (I99I), maior distância formal assinala iconicamente maior distância conceptual. Além disso, maior distância conceptual implica menor controlo por parte do sujeito principal relativamente ao evento subordinado e vice-versa. Assim, a construção com verbo finito, sendo precedida de uma conjunção, está formalmente mais separada do evento principal do que a construção infinitiva. Simultaneamente, a construção finita é conceptualmente mais complexa do que as construções infinitivas. Relativamente às duas construções infinitivas, a construção com Inf Fl está conceptualmente menos vinculada ao evento principal, já que não recupera nenhum dos seus referentes, e o controlo do sujeito principal é menos forte, visto que o Inf Fl remete para um participante específico, que até pode ser distinto do participante principal.

(vi) objetividade/subjetividade (no sentido de Langacker I990, I999): relativamente ao eixo objetivo de per/conceção, a construção com verbo finito é a mais objetiva, na medida em que é ela quem põe em palco todas as componentes do evento subordinado; do ponto de vista do eixo subjetivo de per/conceção, a construção com verbo finito é a mais subjetiva, na medida em que é nela que há mais atualização e um papel mais ativo do locutor na conceptualização do evento, havendo assim lugar para certas elaborações mentais e transferências para outros espaços mentais (Fauconnier I 985). Por exemplo, as duas construções infinitivas de $(3 a)$ e ( 3 b) só podem exprimir a causa propriamente dita, ao passo que $(3 \mathrm{c})$ pode ter uma leitura inferencial, no sentido de que o facto de que as crianças veem o pai permite concluir que elas se alegram.

\section{O significado do infinitivo flexionado}

Da caracterização conceptual feita na secção anterior, podemos concluir que, em comparação com o Inf NF, o Inf Fl exprime maior independência, maior especificidade, maior atualização, maior proeminência, maior distância conceptual, maior elaboração conceptual e maior objetividade. O Inf Fl exprime uma objetificação na conceção do sujeito do infinitivo (ver Soares da Silva 2008). Retomemos os exemplos (I)-(3) e comparemos a construção com Inf Fl em (b) com a construção com Inf NF em (a). A flexão - por si própria, como nos exemplos (b), ou conjuntamente com o sujeito explícito - torna o sujeito do infinitivo mais proeminente no contexto da conceptualização do evento, já que 
fornece informação acerca desse participante. A flexão "põe em palco" o participante principal como foco específico de atenção, como objeto de per/conceção. A flexão de pessoa tende a aumentar a distância entre o evento subordinado e o conceptualizador, fazendo com que o evento ganhe uma certa independência e possa ser visto a partir do "exterior". Deste modo, a flexão de pessoa aumenta a assimetria entre observador e observado e, consequentemente, cria as condições para uma conceptualização objetiva. Tal como Langacker (I99I: 445-449) assinala, há correlação positiva entre a construção objetiva de uma entidade ou situação, a sua menção explícita e uma certa distância conceptual em relação ao conceptualizador: a menção explícita e a distância conceptual têm um efeito objetificador.

Três grupos de fatores podem favorecer a construção com Inf Fl: (i) a autonomia sintático-semântica da oração infinitiva, (ii) a verbalidade da forma infinitiva e o consequente estatuto oracional da construção infinitiva e (iii) a acessibilidade mental do sujeito do infinitivo (Soares da Silva 2008; Vesterinen 20I I; Vanderschueren 20I3). Relativamente à autonomia sintático-semântica, a construção bioracional é, como vimos, favorável à ocorrência de Inf Fl. Um outro fator específico tem a ver com a semântica do conector e da oração subordinada: os conectores temporais (depois de, antes de) e causais (por) compatibilizam-se mais com Inf Fl do que o conector para; de igual modo, as orações temporais e causais, porque conceptualizam o evento como real e factivo, combinam-se melhor com o Inf Fl do que as orações finais, que conceptualizam um evento como virtual (Vanderschueren 20I3: I39I 50). Relativamente ao segundo fator, há uma correlação positiva entre a verbalidade do infinitivo e a ocorrência do Inf Fl. Assim, a forma pronominal do verbo no infinitivo, a presença de reflexivos, a construção passiva, a construção perifrástica, a presença de predicativos e a negação do infinitivo favorecem a ocorrência do Inf Fl. Por outro lado, e como efeito de compensação, o Inf $\mathrm{Fl}$ ocorre mais frequentemente com verbos não dinâmicos do que com verbos dinâmicos. Finalmente, quanto ao terceiro fator, a anteposição e interposição do infinitivo, a pausa e uma maior distância entre infinitivo e antecedente do sujeito do infinitivo dificultam a acessibilidade ao sujeito do infinitivo e, consequentemente, favorecem a construção com Inf Fl (Vesterinen 20I I).

Através de uma rigorosa análise multifatorial de corpus, Vanderschueren (2013: I 89) conclui sobre o impacto dos três fatores autonomia, verbalidade e acessibilidade - na seleção do Inf Fl da seguinte forma, sintetizada na Figura I. 


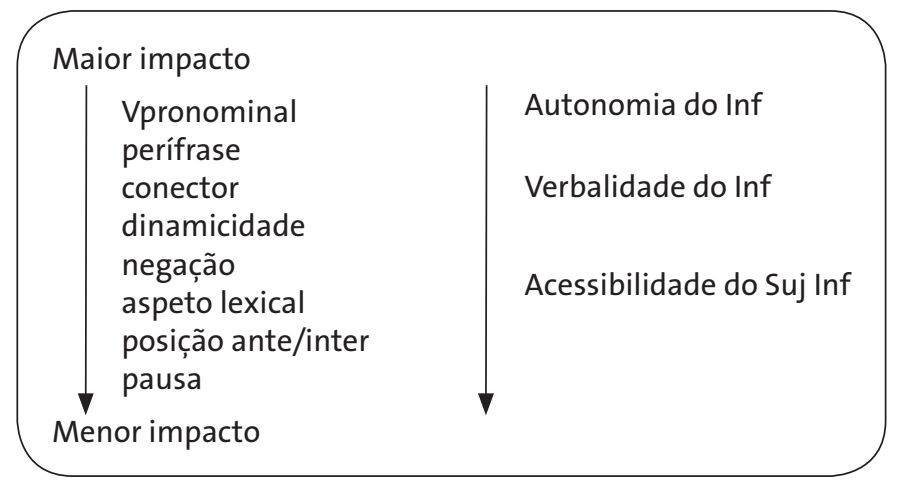

Figura 1. Hierarquia do impacto de fatores na seleção do Inf Fl

\section{Construções completivas infinitivas: verbos causativos e percetivos}

Vamos analisar as construções infinitivas de verbos causativos e percetivos. Para além da construção completiva com verbo finito, as línguas românicas (exceto o romeno) possuem diferentes tipos de construções infinitivas. Uma primeira construção infinitiva é aquela em que o objeto (O) do verbo principal ocorre depois dos dois verbos - é a construção VVO ou, simplesmente, construção VV, exemplificada em (4). Uma segunda construção infinitiva apresenta o objeto entre o verbo principal e o infinitivo - é a construção VOV, como em (5). Os exemplos (4) e (5) do português são igualmente válidos para outras línguas românicas. $\mathrm{O}$ português possui uma terceira construção infinitiva, na qual o objeto é interposto entre os dois verbos mas, ao contrário da anterior, é interpretado como sujeito do infinitivo e este ocorre como Inf Fl: é a construção VSV, como em (6). Embora o galego possua também a construção com Inf Fl, o Inf Fl não ocorre nas construções completivas de verbos causativos e percetivos no galego (Sousa Fernández I999: I76). Além desta variação da ordem de palavras, há também a variação de marcação de caso do sujeito lógico do infinitivo. Ele pode ser codificado como acusativo ou objeto direto (OD), como em (4a, 5a, b), (ii) como dativo ou objeto indireto (OI), como em (4b), (iii) menos frequentemente, como agentivo/instrumental, como em (4c), e (iv) como nominativo ou sujeito em português, necessariamente acompanhado de Inf Fl, como em (6a, b).

Estas variações na ordem das palavras e na marcação de caso do sujeito do infinitivo estão correlacionadas com a valência transitiva/ intransitiva do infinitivo. O padrão correlacional é apresentado no 
Quadro 2, embora haja alguma exceções. Nos casos regulares, as construções intransitivas codificam o sujeito do infinitivo como OD e as transitivas codificam-no como OD na construção VOV e como OI ou outro oblíquo na construção VV. De notar que os verbos de causação interpessoal como forçar (mas não mandar) ocorrem apenas numa construção próxima de VOV, nomeadamente a construção $\mathrm{VOàlaV} \mathrm{em} \mathrm{que} \mathrm{o} \mathrm{infinitivo} \mathrm{é} \mathrm{precedido} \mathrm{pela} \mathrm{preposição} \mathrm{àla.}$

Quadro 2. Propriedades distribucionais das construções infinitivas com verbos causativos e percetivos

\begin{tabular}{|c|c|c|c|c|c|c|}
\hline \multirow{2}{*}{$\begin{array}{l}\text { ordem de } \\
\text { palavras } \\
\text { marcação } \\
\text { de caso }\end{array}$} & \multicolumn{2}{|c|}{ VSV } & \multicolumn{2}{|c|}{ VOV } & \multicolumn{2}{|c|}{ VV } \\
\hline & $\begin{array}{l}\text { INF } \\
\text { intransitivo }\end{array}$ & $\begin{array}{l}\text { INF } \\
\text { transitivo }\end{array}$ & $\begin{array}{l}\text { INF } \\
\text { intransitivo }\end{array}$ & $\begin{array}{l}\text { INF } \\
\text { transitivo }\end{array}$ & $\begin{array}{l}\text { INF } \\
\text { intransitivo }\end{array}$ & $\begin{array}{l}\text { INF } \\
\text { transitivo }\end{array}$ \\
\hline $\begin{array}{l}\text { nominativo - } \\
\text { SUJ }\end{array}$ & $6 a$ & $6 b$ & & & & \\
\hline $\begin{array}{l}\text { acusativo - } \\
\text { OD }\end{array}$ & & & $5 \mathrm{a}$ & $5 \mathrm{~b}$ & $4 \mathrm{a}$ & \\
\hline dativo - OI & & & & & & $4 \mathrm{~b}$ \\
\hline agentivo & & & & & & $4 c$ \\
\hline
\end{tabular}

(4) a. A Maria fez/mandou/deixou/viu correr os miúdos (-os correr).

b. A Maria fez/mandou/deixou/*viu ler esse livro aos miúdos (-lhes ler esse livro).

c. O presidente fez/mandou/(não)?deixou/*viu aprovar a lei pelos deputados.

(5) a. A Maria fez/mandou/deixou/viu os miúdos (-os) correr.

b. A Maria fez/mandou/deixou/viu os miúdos (-os) ler esse livro.

(6) a. A Maria fez/mandou/deixou/viu os miúdos (eles/*-os) correrem.

b. A Maria fez/mandou/deixou/viu os miúdos (eles) lerem esse livro.

VSV, VOV e VV representam três estádios diferentes num continuum de dependência (controlo do sujeito principal e dependência do sujeito subordinado) e de integração estrutural dos eventos principal e subordinado. VSV e VOV são construções bioracionais, sendo VSV mais bioracional do que VOV, ao passo que VV é uma construção monooracional. O Quadro 3 sistematiza as propriedades estruturais destas três construções. ${ }^{2}$ 
Quadro 3. Propriedades estruturais das três construções infinitivas

\begin{tabular}{|c|c|c|}
\hline $\begin{array}{l}\text { Mais independência } \\
\text { do evento complemento }\end{array}$ & & $\begin{array}{l}\text { Menos independência } \\
\text { do evento complemento }\end{array}$ \\
\hline $\begin{array}{l}\text { Menos integração de } \\
\text { eventos }\end{array}$ & & $\begin{array}{l}\text { Mais integração de } \\
\text { eventos }\end{array}$ \\
\hline não-subida do SujInf & $\begin{array}{l}\text { subida SujInf: subida } \\
\text { clíticos }\end{array}$ & $\begin{array}{l}\text { subida SujInf: subida } \\
\text { clíticos }\end{array}$ \\
\hline Inf $\mathrm{Fl}$ & Inf NF & Inf NF \\
\hline não-subida do ObjInf & não-subida do ObjInf & $\begin{array}{l}\text { subida ObjInf: subida } \\
\text { clíticos }\end{array}$ \\
\hline negação encaixada & negação encaixada & $\begin{array}{l}\text { negação encaixada } \\
\text { impossível }\end{array}$ \\
\hline bioracional & bioracional & mono-oracional \\
\hline VSV & VOV & $\mathrm{VV}$ \\
\hline
\end{tabular}

Na construção VSV, o infinitivo apresenta muitas marcas de um verbo independente: preserva as marcas de pessoa e número e toda a sua estrutura argumental, pelo que é impossível qualquer subida do clítico. Além disso, o sujeito lógico do infinitivo é marcado no nominativo, da mesma forma que o sujeito de uma oração independente (SV). Consequentemente, o evento complemento é construído com maior independência. No outro extremo do contínuo, está a construção VV: o infinitivo não tem nenhuma marca de verbo independente e mostra todos os sinais de subida em direção ao verbo principal, donde a subida de todos os clíticos e a impossibilidade da negação. Ou seja: o infinitivo é inteiramente integrado no verbo principal, formando com ele um verbo complexo (VV) e passando os seus argumentos a serem argumentos deste complexo. Nos termos de Raposo (I98 I), VV é uma construção de "união de orações”. Num ponto intermédio, está a construção VOV: o infinitivo preserva grande parte da sua estrutura argumental, sendo o evento complemento ainda visto como independente, mas o sujeito do infinitivo é marcado como objeto direto do verbo principal (VO).

As três construções infinitivas envolvem diferentes perspetivações conceptuais do evento complemento; em termos da Gramática Cognitiva de Langacker (I987, I99I), diferentes organizações figural base ou trajetor/marco. ${ }^{3}$ VSV toma todo o evento complemento como alvo do contacto estabelecido pelo sujeito principal; por outras palavras, 
como marco do verbo principal. VSV perfila pois uma relação indireta entre dois eventos e uma interação entre duas fontes de energia ou dois trajetores. Este conteúdo conceptual faz com que VSV mais se aproxime de uma construção bioracional. Pelo contrário, a construção VOV toma o participante principal do evento complemento como alvo específico do contacto estabelecido pelo sujeito principal, isto é, como marco do verbo principal, mas ao mesmo tempo também o reconhece como fonte de energia ou trajetor do evento complemento, sendo todo o evento complemento tomado como marco secundário do verbo principal. A construção VOV perfila assim uma relação indireta entre dois eventos, embora com uma interação mais direta entre as duas fontes de energia ou trajetores: o sujeito principal interage diretamente com o sujeito do infinitivo, sendo este tomado como ponto de referência para se aceder ao evento complemento. Consequentemente, a construção VOV é menos bioracional do que a construção VSV. Finalmente, a construção VV constrói o participante principal do evento complemento como argumento interno (objeto ou experienciador) de um único complexo verbal e perfila um único evento com uma única fonte de energia, isto é, um único trajetor exercendo controlo sobre o evento como um todo, o que faz de VV uma construção mono-oracional.

A trajetória que vai de VSV a VV pode ser descrita como um processo progressivo de subjetificação ou atenuação no controlo do sujeito: o sujeito lógico do infinitivo perde gradualmente controlo sobre a sua própria atividade ou estado. Esta atenuação conduz a um aumento do grau de integração de eventos e a uma relação mais direta entre os dois eventos. Esta integração construcional e esta relação direta estão iconicamente codificadas nas propriedades estruturais da construção VV indicadas no Quadro 3. Há assim um aumento de gramaticalização da construção VSV para a construção VV: entre as três construções infinitivas, VV representa o grau mais elevado de gramaticalização construcional, ao passo que VSV representa o grau mais baixo. Resumidamente, a escala crescente de integração construcional e gramaticalização é a seguinte: $\mathrm{VSV}>\mathrm{VOV}>\mathrm{VV}$.

Comparemos agora as construções infinitivas de quatro línguas românicas: português, espanhol, francês e italiano. ${ }^{4} \mathrm{~A}$ principal diferença verifica-se com o verbo prototipicamente causativo 'fazer'. Enquanto o francês faire e o italiano fare se combinam necessariamente com a construção mono-oracional VV, o português fazer e o espanhol hacer são compatíveis tanto com VV como com a construção bioracional VOV. O verbo fazer combina-se ainda com a construção mais 
bioracional VSV. Todas as propriedades sintáticas da construção VV referidas acima no Quadro 3 são obrigatórias na construção do francês e do italiano fairelfare + Inf. Além disso, faire + Inf e (geralmente) fare + Inf não podem alternar com a construção de verbo finito, contrariamente ao que se verifica com fazer/hacer + Inf, o que evidencia um grau elevado de integração estrutural nas construções do francês e do italiano.

Comparando as construções dos italiano e do francês, o italiano fare + Inf mostra um grau mais elevado de integração estrutural do que o francês faire + Inf. Prova disso são três propriedades sintáticas da construção faire + Inf:

(i) a possibilidade de interpor o pronome reflexivo se, como em (7);

(ii) a interposição de clíticos com o imperativo na forma positiva, como em (8), e a impermeabilidade no italiano a tal interposição, como em (9);

(iii) a impossibilidade de cliticizar o objeto subordinado junto do verbo principal, como em ( $\mathrm{rob}$ ), contrariamente ao que ocorre no italiano, como em (IOC): 5

(7) Le bruit les fait se lever.

(8) Fais-les-lui planter.

(9) Glie-le voglio far baciare.

(го) a. Je ferai parler Jean a Pierre.

b. "Je lui ferai parler Jean.

c. Ci farò parlare Giovanni.

Há também diferenças de grau de integração de eventos entre as construções do português e do espanhol. O espanhol hacer + Inf apresenta um grau mais elevado de integração estrutural do que o português fazer + Inf. Para além da existência da construção VSV no português, a prova disso está nas seguintes propriedades:

(i) no espanhol, o causado dativo pode ocorrer quer posposto a hacer + Inf quer interposto entre os dois verbos, como em (I Ia), embora a posposição seja mais frequente, ao passo que o português permite apenas a posposição, como se pode ver em (I I b);

(ii) no espanhol, o causado dativo pode ocorrer com infinitivo intransitivo, ao passo que esta construção é dificilmente aceitável no português veja-se (I 2). Neste aspeto, o português segue o padrão regular observado no francês e no italiano;

(iii) no português, a construção mais frequente é VOV quando o causado é [+ HUM] e quando o infinitivo é transitivo (ver Soares da Silva 2005), como em (I 3 a), ao passo que no espanhol a construção mais frequente é claramente VV, como em (I 3 b). 
( I I) a. Juan hizo a su mujer traer un regalo. (Cano Aguilar I98 I: 243)

b. *O João fez à sua mulher trazer um presente.

(I2) a. Le hice correr.

b. ??Fiz-lhe correr.

(I3) a. O João fez a sua mulher trazer um presente.

b. Juan hizo traer un regalo a su mujer.

A Figura 2 representa a escala crescente de integração estrutural de eventos e, assim, de gramaticalização construcional nas construções completivas infinitivas do verbo causativo 'fazer' nas quatro línguas românicas. A construção mais gramaticalizada é a do italiano fare + Inf, seguida da construção do francês faire + Inf. A seguir, vem a construção do espanhol hacer + Inf e, por último, como construção menos gramaticalizada, o português fazer + Inf. As três propriedades sintáticas analisadas nos exemplos (7)-(IO) e (I I )-(I3) confirmam esta afirmação.

$$
\text { fazer }+ \text { Inf hacer }+ \text { Inf faire }+ \text { Inf fare }+ \text { Inf }
$$

Figura 2. Escala de gramaticalização nas construções causativas românicas ('fazer' + Inf)

Em relação às construções causativas com o verbo 'deixar', há menos diferenças entre as línguas românicas. De qualquer forma, a construção do português deixar + Inf é a que apresenta um grau menor de gramaticalização construcional: para além do facto de que deixar participa na construção menos integrada VSV, a construção dominante é VOV com infinitivos transitivos, tanto sincrónica como diacronicamente (ver Soares da Silva I999, 2005). O mesmo se diga em relação a mandar + Inf. Na verdade, a existência da construção VSV é suficiente para que as construções infinitivas do português possuam um grau mais baixo de gramaticalização do que as mesmas construções no espanhol, francês e italiano.

A Figura 3 representa a escala crescente de gramaticalização construcional nas construções completivas infinitivas, tendo num extremo a construção bioracional do português VSV e no outro extremo a construção mono-oracional do italiano VV.

PtVSV Pt/Sp/Fr/ItVOV PtVV SpVV FrVV ItVV

Figura 3. Escala de gramaticalização construcional nas construções completivas infinitivas do português, espanhol, francês e italiano 


\section{6. (Des)gramaticalização}

As construções infinitivas com verbos causativos e percetivos têm origem no latim (ver Norberg 1974 e Chamberlain I986). O latim teve a construção completiva com verbo finito e conjunção $u t$ e a construção completiva infinitiva, exemplificadas em (I 4)-(I 5 ). A construção infinitiva tornou-se mais frequente do que a construção finita no latim tardio (ou, pelo menos, nos primórdios das línguas românicas). A construção infinitiva latina apresentava uma estrutura com acusativo (accusativus cum infinitivo) e uma outra com dativo (dativus cum infinitivo).

No latim clássico, iubere 'ordenar' era o verbo causativo prototípico. Era geralmente seguido de uma completiva com $u t$ e conjuntivo ou da construção accusativus cum infinitivo, como em (I4). Também o verbo facere 'fazer' podia ser usado nestas construções causativas, como em ( I 5), embora menos frequentemente.

(I4) a. Populus Romanus iussit ut Sullae voluntas esset pro lege. (Cerbasi I997: I66)

'O povo romano ordenou que a vontade de Sulla fosse tornada lei'

(I4) b. iusserunt simulacrum Iouis facere maius (Cícero, Catiline, 3.20)

'Mandaram construir uma estátua de Júpiter maior'

(15) a. Faciam ut ejus diei locique meique semper meminerit. (Plauto, Captivi, 4.6.3)

'Fá-lo-ei lembrar-se sempre de mim, do seu dia e do seu lugar'

(15) b. Qui nati coram me cernere letum fecisti. (Virgilio, Aeneid 2, 538-539)

'(Tu) que me obrigaste a assistir à morte do meu filho'

Foi a partir do verbo causativo iubere que a construção infinitiva com acusativo (accusativus cum infinitivo) se espalhou a outros verbos, como facere. A construção exemplificada em ( I 5 b) é, pois, o antepassado das construções causativas infinitivas nas línguas românicas. Chamberlain ( I 986) observa que, a partir do séc. V, a construção facere + Inf (em vez de facere $+u t$ ) começou a difundir-se tornando-se a construção mais frequente a partir do séc. VI. Norberg (I974) e Chamberlain (I986) sugerem que as construções causativas de grau mais elevado de integração de eventos, isto é, as construções mono-oracionais se desenvolveram nos últimos períodos do latim.

As construções completivas infinitivas estavam já estabelecidas no período antigo das línguas românicas (ver Chamberlain I986, Herman I989, Pearce I990, Davies I995, Soares da Silva I999, Sousa Fernández I999, Vieira da Silva 2003), o que pode ser justificado com 
base em quatro factos linguísticos. Em primeiro lugar, a complementação infinitiva aparece como opção padrão (em vez da complementação com verbo finito) nos textos latino-românicos, tanto nos textos latino-gauleses dos sécs. VI e XI (Chamberlain I986), como nos textos latino-ibéricos dos sécs. XI e XII (Vieira da Silva 2003). Em segundo lugar, a construção mono-oracional consolidou-se nos textos latino-românicos e nos textos do período antigo das línguas românicas, tornando-se por vezes mais frequente do que a construção bioracional. Chamberlain (I986: I35) sugere que as duas construções com o latim facere e o francês faire já existiam no latim tardio e no francês antigo em variação livre, embora a construção mono-oracional fosse mais frequente do que a construção bioracional. Em terceiro lugar, verifica-se nesses períodos o desenvolvimento da construção dativus cum infinitivo (que, segundo Norberg 1974, é de origem latina), a ponto de se tornar mais frequente do que a construção mais antiga com acusativo. Finalmente, a correlação entre marcação de caso do sujeito do infinitivo e padrão sintático (intransitivo/transitivo) do infinitivo, típica das línguas românicas, remonta ao período antigo das línguas românicas. Tudo isto mostra uma evolução das construções infinitivas no sentido da gramaticalização construcional.

Desde os primeiros estágios das línguas românicas, as construções infinitivas com o verbo causativo 'fazer' apresentam um grau mais elevado de integração estrutural do que as construções infinitivas com o verbo causativo 'deixar' ou o verbo ibérico 'mandar'. Há, porém, uma divergência entre as línguas românicas na evolução das construções infinitivas com 'fazer': de um lado, o francês e o italiano faire/fare + Inf perdem a construção bioracional VOV e a construção com verbo finito e conjuntivo; do outro lado, o português e o espanhol fazer/hacer + Inf mantêm a alternância entre a construção mono-oracional VV, a construção bioracional VOV e a construção com verbo finito. Quer isto dizer que o francês e o italiano fairelfare + Inf evoluíram no sentido de um aumento de gramaticalização. Já o português e o espanhol evoluíram, como veremos melhor a seguir, no sentido inverso, e isso aconteceu não só com os verbos causativos como com outros verbos que selecionam complemento infinitivo.

Vejamos mais de perto o desenvolvimento das construções infinitivas no português e espanhol. No seu estudo acerca da evolução das construções causativas no espanhol e no português, Davies (I995, 2000) conclui que o português e o espanhol são as línguas românicas em que se verificam maiores mudanças na evolução das construções causativas 
infinitivas, independentemente do verbo causativo, e essas mudanças configuram uma mudança geral que vai da estrutura mono-oracional para a estrutura bioracional. Ainda segundo Davies, estas mudanças terão começado com os verbos de perceção como ver e ouvir/oír e depois ter-se-ão espalhado aos verbos causativos, inicialmente, deixar/dejar, permitir, obrigar/obligar e ordenar e, finalmente, aos verbos causativos prototípicos fazer/hacer e mandar. Também Martins (2004, 2006) analisa estas mudanças das construções infinitivas dos verbos causativos e percetivos, mas integra-as no contexto de uma mudança mais geral das construções infinitivas do português que vai de estruturas "mais reduzidas" a estruturas "menos reduzidas" e afeta não só verbos causativos e percetivos mas também verbos de controlo, como querer, e verbos de elevação, como o verbo modal poder.

Tendo em conta estes estudos diacrónicos de Davies (I995, 2000) e de Martins (2004, 2006) e com base numa análise de corpus, ${ }^{6}$ identificamos seis mudanças sintáticas nas construções infinitivas, que ocorreram mais rápida e acentuadamente no português do que no espanhol e que começaram por afetar os verbos percetivos e os verbos perifericamente causativos e se espalharam depois aos verbos prototipicamente causativos (Soares da Silva 20I Ib):

(i) cliticização no infinitivo, isto é, não subida dos clíticos

(ii) emergência do pronome se no complemento infinitivo $\left(\mathrm{F}_{2}\right)$

(iii) mudança no caso do sujeito do infinitivo transitivo: de dativo para acusativo

(iv) emergência da negação no complemento infinitivo $\left(\mathrm{F}_{2}\right)$

(v) mudança de ordem das palavras no complemento infinitivo $\left(\mathrm{F}_{2}\right)$ : de VS para SV

(vi) emergência do Inf Fl em português a partir do séc. XVI nos complementos dos verbos causativos e percetivos ${ }^{7}$

Estas mudanças estão exemplificadas no Quadro 4, nos exemplos ( I 6c, d)-(2 Ic, d) do português e do espanhol médios e modernos, em contraste com os exemplos ( $16 a, b)-(2 \mathrm{I} a, b)$ do português e espanhol antigos.

Comentando muito brevemente estas mudanças, a análise de corpus mostra que até ao séc. XVI a norma é a subida dos clíticos e que a tendência para a cliticização no infinitivo se torna mais clara apenas nos séc.s XIX e XX. É o verbo hacer/fazer o que mais resiste a esta mudança. Em relação à segunda mudança, os primeiros usos de se no complemento infinitivo ocorrem no séc. XVI e com maior frequência com os verbos de perceção e o verbo permissivo deixar/dejar 
do que com os verbos fazer/hacer e mandar. A tendência para o uso do se no complemento infinitivo torna-se mais clara apenas no português e espanhol modernos. Quanto à terceira mudança, há uma diminuição clara do uso do clítico dativo ao longo do tempo, mais acentuada com infinitivos transitivos. A mudança é mais lenta no espanhol do que no português. Em relação à quarta mudança, é a partir do séc. XVI que se verifica uma maior tendência para a ocorrência da negação predicativa no complemento infinitivo. Quanto à quinta mudança, verifica-se ao longo do tempo um aumento da ordem SV, claramente mais nítida no português do que no espanhol e maior com os verbos percetivos e deixar/dejar. Finalmente, é a partir do séc. XVI que se encontram no português as primeiras ocorrências do Inf Fl nos complementos dos verbos percetivos e causativos.

Quadro 4. Mudanças da construção infinitiva mono-oracional do português e espanhol antigos para a construção infinitiva bioracional do português e espanhol médios e modernos

\begin{tabular}{|c|c|}
\hline $\begin{array}{l}\text { Português/Espanhol antigos + } \\
\text { subida dos clíticos }\end{array}$ & $\begin{array}{l}\text { Português/Espanhol médios e modernos - } \\
\text { subida dos clíticos }\end{array}$ \\
\hline $\begin{array}{l}\text { (I 6a) e outrossi lhe fez dar } \\
\text { muy grande côtia en dinheiros } \\
\text { (Cron. I344) }\end{array}$ & $\begin{array}{l}\text { ( } 6 \mathrm{cc} \text { ) Se vai ao Castelhano, prome- } \\
\text { tendo Que ele faria dar-lhe obediência } \\
\text { (Camões, Obras, I } 5 \text { ??) }\end{array}$ \\
\hline $\begin{array}{l}\text { ( I6b) non gelo dexaron sacar } \\
\text { del canpo (Hist Troy } \mathrm{I} 253 \text { ) }\end{array}$ & $\begin{array}{l}\text { (I6d) nos iba a dejar sacarlo (Gazapo, } \\
\text { I9??) }\end{array}$ \\
\hline$-s e$ em $\mathrm{F}_{2}$ & $+s e$ em $\mathrm{F}_{2}$ \\
\hline $\begin{array}{l}\text { (I7a) Et el rrey o fezera cobrir } \\
\text { de hîa púrpura negra moy } \\
\left.\text { preçada (CronTroyana } \mathrm{I}_{3} 88\right)\end{array}$ & $\begin{array}{l}\text { (I7c) ela fará ao marido cobrir-se de } \\
\text { tinha e muito mais que ela (Gil Vicente, } \\
\text { I 5??) }\end{array}$ \\
\hline $\begin{array}{l}\text { ( } \mathrm{I} 7 \mathrm{~b}) \text { conuidaua los \& fazie los } \\
\text { assentar (GenEst } \mathrm{I} 272)\end{array}$ & $\begin{array}{l}\text { (I7d) los oye sacudirse como si temieran } \\
\text { que algo les caiga (Caballo I9??) }\end{array}$ \\
\hline Suj. Inf-Tr: Dativo & Suj. Inf-Tr: Acusativo \\
\hline $\begin{array}{l}\text { (I 8a) e que lhe rogava que lhe } \\
\text { leixasse veer o conde (Cron. } \\
\text { I344) } \\
\text { (I8b) o le fazen perder la } \\
\text { onrra o el señorio que ante } \\
\text { auia (Alfonso X, Siete Partidas, } \\
\text { I260) }\end{array}$ & $\begin{array}{l}\text { ( I8c) pediu licença ao Capitão-mor, que } \\
\text { em companbia deles o deixasse ir ver } \\
\text { aquele Mosteiro (Barros, Ásia, I } 5 \text { ??) } \\
\text { ( I8d) la fazen forçosamente confessar } \\
\text { el contrario de lo que sienten (Celestina, } \\
\text { I499) }\end{array}$ \\
\hline
\end{tabular}




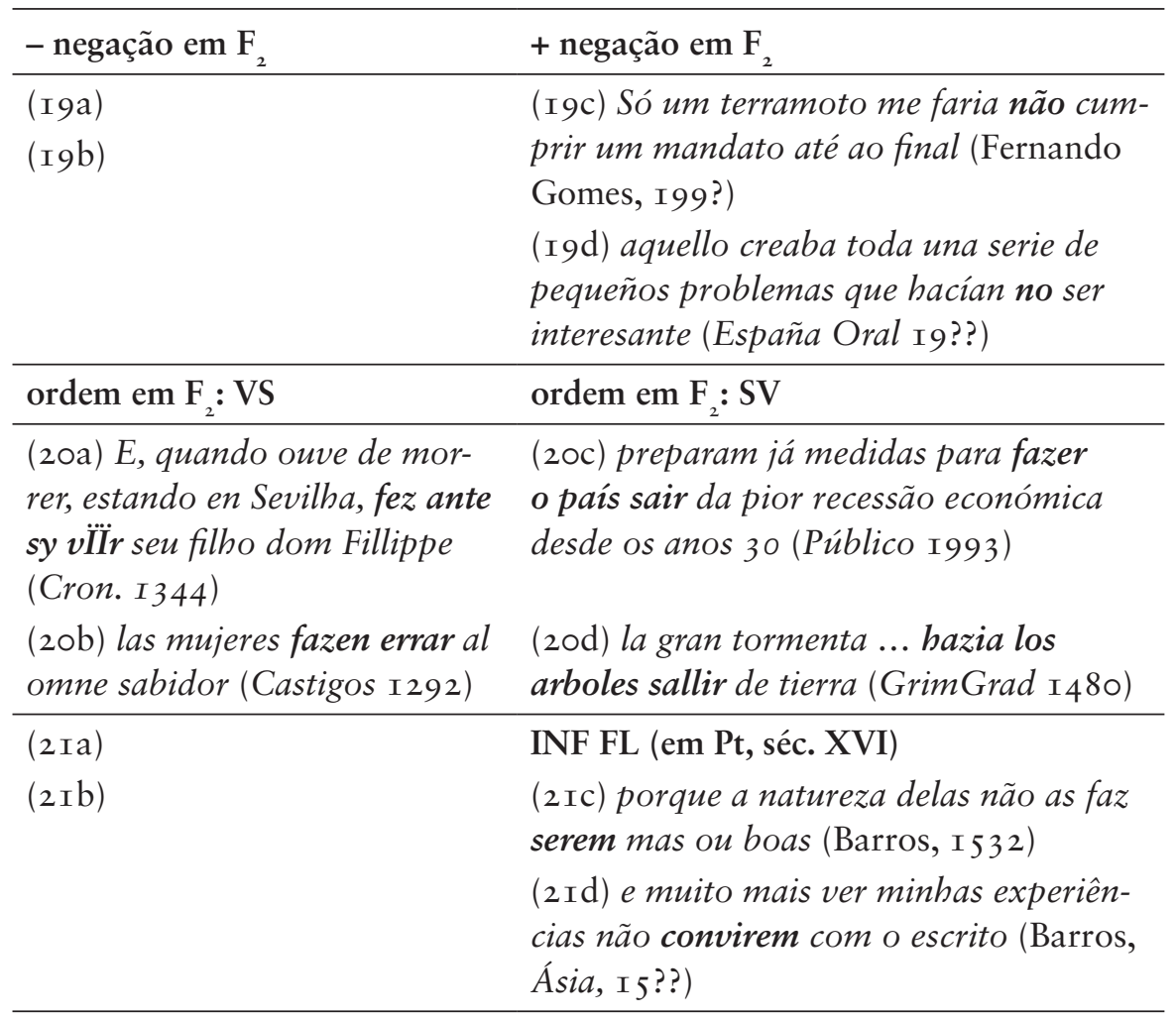

Estas seis mudanças sintáticas específicas e esta mudança geral de uma estrutura mono-oracional para uma estrutura bioracional configuram um processo de desgramaticalização que envolve uma atenuação gradual das propriedades sintáticas e semânticas da estrutura monooracional (ou, na perspetiva inversa, um reforço gradual das propriedades sintáticas e semânticas da construção bioracional). Explicaremos este processo de desgramaticalização na secção seguinte. Quanto às causas desta mudança, Davies (I995) sugere que o uso gradualmente crescente de sujeitos do infinitivo explícitos a partir do período médio nos complementos dos verbos causativos e percetivos está na origem das mudanças da estrutura mono-oracional para a estrutura bioracional, ao passo que Martins $(2004,2006)$ encontra a origem destas mudanças na existência de frases estruturalmente ambíguas envolvendo coordenação, elipse e orações independentes de Inf Fl com valor imperativo (que já se encontravam na gramática do português antigo).

A emergência do Inf Fl nos complementos dos verbos percetivos e causativos a partir do séc. XVI é a manifestação mais clara desta tendência desgramaticalizante. Este facto coloca o português num estádio 
menos avançado de gramaticalização das construções infinitivas, em comparação com outras línguas românicas. A maior proximidade da construção com Inf Fl à construção bioracional VOV do que à construção mono-oracional VV terá favorecido o uso do Inf Fl.

Ainda em relação ao português, os dados disponíveis nos textos medievais mostram que a construção VV e a construção VOV já coexistiam no português antigo e que a construção mono-oracional VV era mais frequente no português antigo do que a construção bioracional VOV e ainda mais com infinitivo intransitivo e sujeito geralmente marcado no dativo (Vieira da Silva 2003). Quer isto dizer que a hipótese segundo a qual a mudança do português antigo ao português moderno se deveu à emergência da construção bioracional não se confirma. $\mathrm{O}$ que aconteceu foi que a partir do séc. XVI a construção bioracional reforçou a independência do complemento infinitivo, introduzindo nele propriedades estruturais de menor integração do evento complemento no evento principal.

O nosso estudo diacrónico sobre o verbo deixar e seus correspondentes noutras línguas (Soares da Silva I999, 2007) e o nosso estudo sincrónico sobre as construções infinitivas dos verbos causativos e percetivos no português contemporâneo (Soares da Silva 2005) mostram uma outra mudança nas construções infinitivas que Davies (I995) não refere. Trata-se de um aumento gradual da construção mono-oracional VV com verbos causativos e infinitivo intransitivo, pelo menos em português, e o seu claro predomínio no português europeu contemporâneo.

Estes resultados sugerem uma dupla tendência na evolução das construções infinitivas no português e no espanhol. Por um lado, temos uma desgramaticalização construcional, mais rápida e mais nítida no português do que no espanhol. Esta desgramaticalização é a razão pela qual o português e o espanhol divergem do francês e do italiano na evolução das construções infinitivas com verbos causativos e percetivos. Por outro lado, o aumento da construção mono-oracional VV com verbos causativos e infinitivo intransitivo mostra que o português e o espanhol seguem, até certo ponto, a tendência gramaticalizante geral que se observa nas línguas românicas, em particular no italiano e no francês.

\section{Motivações conceptuais: subjetificação e objetificação}

O processo diacrónico de gramaticalização das construções infinitivas dos verbos causativos e percetivos que ocorreu no francês e no italiano, especialmente com o verbo causativo fairelfare, e no português 
e no espanhol nas construções com infinitivo intransitivo consiste num processo conceptual de subjetificação ou atenuação do controlo do sujeito e consequente mudança de um sujeito ativo para o conceptualizador (Langacker I999). O sujeito do infinitivo vai gradualmente perdendo controlo sobre a sua própria atividade ou estado e deixa de ser o foco específico do evento complemento. A atividade ou fonte de energia passa do domínio do sujeito do infinitivo para o domínio do sujeito principal. O sujeito principal torna-se assim o conceptualizador do evento complemento, exercendo maior controlo sobre o evento complemento. Consequentemente, a relação causal ou percetiva torna-se mais direta e imediata e mais dependente da atividade mental do conceptualizador e, portanto, mais subjetiva. Em termos da abordagem de Traugott (I989, I995) ao fenómeno da subjetificação, a relação causal/percetiva torna-se cada vez mais situada no domínio do conceptualizador - o sujeito principal e/ou o locutor. Estruturalmente, surgem determinadas propriedades sintáticas que iconicamente codificam um maior grau de integração construcional e, consequentemente, de gramaticalização.

O processo diacrónico inverso de desgramaticalização que ocorre no português e no espanhol e apresenta a sua manifestação mais visível na emergência do Inf $\mathrm{Fl}$ no português consiste num processo conceptual de objetificação do sujeito do infinitivo. O participante principal do evento subordinado torna-se mais independente e mais comprometido na realização do evento; entra "em palco" como foco específico de atenção e, portanto, como objeto de conceptualização. Esta promoção do sujeito do infinitivo cria uma distância entre o evento complemento e o conceptualizador, pelo que o evento complemento ganha uma certa independência e pode ser visto "desde o exterior", recebendo assim as propriedades estruturais dessa autonomia. A construção do português com Inf Fl exprime a conceptualização mais objetiva do evento subordinado.

\section{Conclusões e investigação futura}

As construções completivas infinitivas estão menos gramaticalizadas no português e no espanhol do que no italiano e no francês. Verifica-se um contínuo decrescente de gramaticalização que começa no italiano, a seguir o francês, depois o espanhol e finalmente o português. Vimos que a construção do italiano fare + Inf está mais gramaticalizada do que a construção do francês faire + Inf e que a 
construção do espanhol hacer + Inf está mais gramaticalizada do que a construção do português fazer + Inf. Tudo isto confirma grande parte da hipótese de De Mulder \& Lamiroy (2008) de uma escala decrescente de gramaticalização nas línguas românicas, que começa no francês, passa para o italiano, depois o espanhol e finalmente o português e o romeno.

O português e o espanhol mostram um interessante processo gradual de desgramaticalização das construções infinitivas com verbos causativos e percetivos e com verbos de controlo e elevação, do período antigo para o período atual, situando-se por isso num estádio mais recuado de gramaticalização destas construções no conjunto das línguas românicas. Esta desgramaticalização desenvolveu-se mais rápida e intensamente no português do que no espanhol e envolveu a perda da subida obrigatória dos clíticos, a alteração do caso do sujeito do infinitivo do dativo para o acusativo, a mudança da ordem VS para SV, o surgimento do pronome se e da negação predicativa no complemento infinitivo e, no caso do português nos complementos dos verbos causativos e percetivos, a emergência do Inf Fl.

A evolução das construções infinitivas mostra que os processos de gramaticalização e de desgramaticalização se podem combinar. A desgramaticalização no português e no espanhol não impediu que as mesmas construções infinitivas em determinados contextos, designadamente com verbos causativos e infinitivos intransitivos, seguissem a tendência geral de gramaticalização construcional.

A (des)gramaticalização das construções infinitivas envolve fatores conceptuais de perspetivação e fatores estruturais de integração de eventos. A desgramaticalização das construções infinitivas no espanhol e, mais acentuadamente, no português envolve um processo conceptual de objetificação do evento subordinado e do seu sujeito. A gramaticalização das construções infinitivas no italiano e no francês e, com os verbos causativos e infinitivo intransitivo, no espanhol e no português envolve um processo conceptual de subjetificação ou atenuação do controlo do sujeito do infinitivo.

As línguas românicas revelam uma maior atenção perspetival às diferentes partes e relações do evento codificado na construção infinitiva e um contínuo maior de integração de eventos do que as línguas germânicas. Crucialmente, o português evidencia maior elaboração do evento codificado na construção infinitiva, maior atenção perspetival às partes desse evento e maior flexibilidade conceptual e construcional do que as outras línguas românicas. O Inf Fl do português marca maior 
autonomia e maior objetividade na conceptualização do evento codificado na oração infinitiva.

Os dados diacrónicos evidenciam as diferenças de perspetivação conceptual entre as diferentes construções infinitivas das línguas românicas. Mais especificamente, os dados diacrónicos são uma boa evidência empírica da adequação da abordagem cognitiva das diferenças entre a construção infinitiva mono-oracional VV, a construção infinitiva bioracional VOV e a construção infinitiva mais bioracional do português VSV, cuja melhor identificação é a ocorrência do Inf Fl.

Obviamente que é necessária mais investigação diacrónica e sincrónica sobre as construções infinitivas nas línguas românicas. Sugerimos três tópicos de investigação. Primeiro, são necessárias mais análises de corpus quantitativas e multifatoriais que possam confirmar a escala de gramaticalização das construções infinitivas nas línguas românicas aqui sugerida e permitam definir com maior rigor as motivações, os mecanismos e a cronologia das mudanças sintáticas e semânticas. Especificamente, a maior gramaticalização do italiano fare + Inf em comparação com o francês faire + Inf e a maior gramaticalização do espanhol hacer + Inf em comparação com o português fazer + Inf precisam de uma análise de corpus mais extensa. Um segundo tópico de investigação consiste em identificar os fatores sociolinguísticos e sócio-históricos que contribuíram para os diferentes estádios de (des) gramaticalização das construções infinitivas e ver como esses fatores sociais se correlacionam com os fatores conceptuais e estruturais aqui identificados. Finalmente, é importante desenvolver o estudo dos processos de (des)gramaticalização no vasto contexto das construções infinitivas, comparando as construções completivas (com verbos causativos, percetivos, de controlo e elevação) e as construções adverbiais. Uma questão relevante é saber até que ponto o significado da construção influencia o processo de (des)gramaticalização e até que ponto este processo é influenciado pelo significado do verbo principal e/ou do verbo subordinado.

\section{Notas}

I. Para mais desenvolvimento, ver Soares da Silva (2008).

2. Para uma análise mais desenvolvida, ver o estudo pioneiro de Raposo (I98 I) e a análise de corpus de Soares da Silva (2005).

3. Para uma análise mais desenvolvida, ver Soares da Silva (2004, 2005). 
4. Para um estudo mais desenvolvido em relação à gramaticalização das construções causativas nestas quatro línguas românicas, ver Soares da Silva (20I2).

5. Burzio (I978: 25) dá o seguinte exemplo como gramatical: "Gli lascerò parlare Giovanni” (Deixarei Giovanni falar com ele). Todavia, esta frase dificilmente é aceitável. A prova disso é que não encontramos nenhum exemplo semelhante a este no Google.

6. O corpus de análise inclui o Corpus do Português (45 milhões de palavras, do séc. XIV ao séc. XX), de M. Davies e M. Ferreira, e o Corpus del Español ( Ioo milhões de palavras, do séc. XIII ao séc. XX), de M. Davies. Agradeço a M. Davies algumas informações sobre o uso destes corpora.

7. O Inf Fl não é opção com verbos de controlo nem de elevação, visto que estes verbos não permitem um sujeito subordinado referencialmente independente.

\section{Referências}

\section{Corpora (exemplos citados)}

\section{Cícero:}

Cicero, Marcus Tullius. I 869. Ciceros Reden gegen L. Catilina für den Schulgebrauch, herausgegeben von F. Richter. Leipzig: Teubner; disponível sob: http://books.google.se/books?id=ZZc9AAAAcAAJ (09/05/2013).

Davies, Mark. 2002-. Corpus del Español: Ioo million words, I200s-I90os, disponível sob: http://www.corpusdelespanol.org (06/05/2013).

Davies, Mark \& Michael Ferreira. 2006-. Corpus do Português: 45 million words, I300s-I90os, disponível sob: http://www.corpusdoportugues.org (06/05/20I3).

\section{Plauto:}

Plautus, Titus Maccius. I 843. The Captives: A Comedy of Plautus with English notes for the use of students by John Proudfil. New York: Harper; disponível online: http://books.google.se/books?id=kwrZxPlB4JYC\&printsec (09/05/2013).

Virgílio:

Virgilius Maro, P[ublius]. I854. P[ublii] Virgilii Maronis opera, editit Hermannuns Paldamus. Lipsiae : Karl Tauchnitz, disponível online: http://

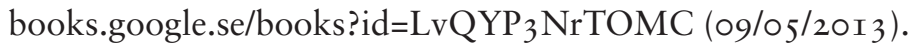

\section{Obras citadas}

Burzio, Luigi. I978. "Italian causative constructions". Journal of Italian Linguistics, 2: I-7I. 
Bybee, Joan L. 2003. "Mechanisms of change in grammaticization: The role of repetition". In: Joseph, Brian D. \& Richard D. Janda (eds.). Handbook of Historical Linguistics. Oxford: Blackwell. 602-623.

Cano Aguilar, Rafael. I98I. Estructuras sintácticas transitivas en el español actual. Madrid: Gredos.

Cerbasi, Donato. I997. "Las construcciones causativas del tipo hacer + Infinitivo en español, portugués e italiano”. Lingüística Española Actual, I 9:2. I 55-I7I.

Chamberlain, Jeffrey T. I986. Latin antecedents of French causative faire. New York: Peter Lang.

Cristofaro, Sonia. 2007. "Deconstructing categories: finiteness in a functional-typological perspective”. In: Nikolaeva, Irina (ed.). Finiteness. Theoretical and Empirical Foundations. Oxford: Oxford University Press, 9 I-I I4.

Davies, Mark. I995. "The evolution of causative constructions in Spanish and Portuguese”. In: John Amastae, Grant Goodall, Mario Montalbetti \& Marianne Phinney (eds.). Current research in Romance Linguistics: papers from the 22nd Linguistic Symposium on Romance Languages El Paso, Cd. Juárez, February I992. Amsterdam: John Benjamins. I05-I 22.

Davies, Mark. 2000. "Syntactic diffusion in Spanish and Portuguese infinitival complements". In: Dworkin, Steven \& Dieter Wanner (eds.). New approaches to old problems: Issues in Romance Historical Linguistics. Amsterdam: John Benjamins. I09-I 27.

De Mulder, Walter \& Béatrice Lamiroy. 2008. "Different stages of grammaticalization: the position of French among the Romance languages". Paper presented at $4^{\text {th }}$ International Conference "New Reflections on Grammaticalization”. University of Leuven, I6-I9 July 2008.

Fauconnier, Gilles. I985. Mental Spaces. Cambridge, Mass.: The MIT Press.

Givón, Talmy. I99I. "Isomorphism in the grammatical code: cognitive and biological considerations". Studies in Language, I 5. 85-I I 4.

Haiman, John. I980. "The iconicity of grammar: isomorphism and motivation”. Language, 56. 5 I 5-540.

Herman, Jozsef. I989. "Accusativus cum infinitivo et subordonnée à quod, quia en latin tardif”. In: Calboli, Gualtiero (ed.). Subordination and other topics in Latin. Proceedings of the Third Colloquium on Latin Linguistics, Bologna, I-5 April I985. Amsterdam: John Benjamins. I33-I 52.

Hopper, Paul J. \& Elizabeth C. Traugott. 2003. Grammaticalization. $2^{\text {nd }}$ ed. Cambridge: Cambridge University Press. 
Langacker, Ronald W. I987. Foundations of Cognitive Grammar. I. Theoretical prerequisites. Stanford: Stanford University Press.

Langacker, Ronald W. I990. “Subjectification”. Cognitive Linguistics, I:I. 5-38.

Langacker, Ronald W. I99 I. Foundations of Cognitive Grammar. 2. Descriptive application. Stanford: Stanford University Press.

Langacker, Ronald W. I999. "Losing control: grammaticalization, subjectification, and transparency”. In: Blank, Andreas \& Peter Koch (eds.). Historical semantics and cognition. Berlin / New York: Mouton de Gruyter. I47-I75.

Langacker, Ronald W. 2008. Cognitive Grammar. A basic introduction. Oxford: Oxford University Press.

Martins, Ana Maria. 2004. "Ambiguidade estrutural e mudança linguística: A emergência do infinitivo flexionado nas orações complemento de verbos causativos e perceptivos”. In: Brito, Ana, Olívia Figueiredo \& Clara Barros (eds.). Linguística Histórica e História da Língua Portuguesa. Actas do Encontro de Homenagem a Maria Helena Paiva. Porto: Faculdade de Letras da Universidade do Porto. I97-225.

Martins, Ana Maria. 2006. "Aspects of infinitival constructions in the history of Portuguese”. In: Randall Scott Gess, \& Deborah Arteaga (eds.). Historical Romance Linguistics: Retrospective and perspectives. Amsterdam: John Benjamins. 327-355.

Norberg, Dag. I974. «Faire faire quelque chose à quelqu'un ». Recherches sur l'origine latine de la construction romane. In : Norberg, Dag (ed.). Au Seuil du Moyen Age. Études linguistiques, métriques et littéraires publiées par ses collègues et élèves à l' occasion de son 65 e anniversaire. Padova: Antenore. I 6-6o.

Pearce, Elizabeth. I990. Parameters in Old French syntax: infinitival complements. Dordrecht: Kluwer.

Raposo, Eduardo Paiva.r98I. A construção "união de orações” na gramática do português. Dissertação de Doutoramento. Universidade de Lisboa.

Soares da Silva, Augusto. I999. A Semântica de deixar: Uma contribuição para a abordagem cognitiva em Semântica Lexical. Lisboa: Fundação Calouste Gulbenkian.

Soares da Silva, Augusto. 2004. "Imagery in Portuguese causation/perception constructions”. In: Lewandowska-Tomaszczyk, Barbara \& Alina Kwiatkowska (eds.). Imagery in language. Festschrift in honour of Professor Ronald W. Langacker. Frankfurt am Main: Lang. 297-3I9.

Soares da Silva, Augusto. 2005. "Revisitando as construções causativas e perceptivas em português: significado e uso". In: Duarte, Inês \& Isabel Leiria 
(eds.). Actas do XX Encontro Nacional da Associação Portuguesa de Linguística (Lisboa I3, I4 e I5 de Outubro de 2004). Lisboa: Associação Portuguesa de Linguística. 85 5-874 [disponível online: http://www.apl.org. pt/docs/actas-20-encontro-apl-2004.pdf (último acesso: 02/06/20I3)].

Soares da Silva, Augusto. 2007. "Verbs of letting: Some cognitive and historical aspects". In: Delbecque, Nicole \& Bert Cornillie (eds.). On interpreting construction schemas. From action and motion to transitivity and causality. Berlin \& New York: Mouton de Gruyter. I7I-200.

Soares da Silva, Augusto. 2008. "The Portuguese inflected infinitive and its conceptual basis". In: Lewandowska-Tomaszczyk, Barbara (ed.). Asymmetric events. Amsterdam: John Benjamins. 225-24I.

Soares da Silva, Augusto. 2or ra. "(Inter)subjetificação na linguagem e na mente". Revista Portuguesa de Humanidades - Estudos Linguísticos, I 5:I. 93-IIO.

Soares da Silva, Augusto. 20Irb. "Gramaticalización y desgramaticalización en las construcciones de infinitivo con verbos causativos y perceptivos en portugués y en español". Comunicação apresentada no International IberoRomance Linguistics Conference, University of Leuven, 3-5 fevereiro.

Soares da Silva, Augusto. 20I2. "Stages of grammaticalization of causative verbs and constructions in Portuguese, Spanish, French and Italian”. Folia Linguistica, 46:2. 513-552.

Sousa Fernández, Xulio. I998. Estudio diacrónico das construccións con mandar como verbo de orde en galego. Tesis Doctoral. Universidad de Santiago de Compostela.

Traugott, Elizabeth C. 1989. "On the rise of epistemic meanings in English: an example of subjectification in semantic change". Language, 65. 3 I-55.

Traugott, Elizabeth C. 1995. "Subjectification in grammaticalisation". In: Stein, Dieter \& Susan Wright (eds.). Subjectivity and Subjectivisation. Linguistic Perspectives. Cambridge: Cambridge University Press. 3 I-54.

Traugott, Elizabeth C. 2003. "Constructions in grammaticalization". In: Joseph, Brian D. \& Janda, Richard D. (eds.). The handbook of historical linguistics. Oxford: Blackwell. 624-647.

Traugott, Elizabeth C. 2008. "Grammaticalization, constructions and the incremental development of language: Suggestions from the development of degree modifiers in English”. In: Eckardt, Regine, Gerhard Jäger \& Tonjes Veenstra (eds.). Variation, selection, development: Probing the evolutionary model of language change. Berlin / New York: Mouton de Gruyter. 2I9-250. 
Vanderschueren, Clara. 2013. Infinitivo y Sujeto en Portugués y Español. Un estudio empírico de los infinitivos adverbiales con sujeto explícito. Berlin/ New York: Mouton de Gruyter.

Vesterinen, Rainer. 20I I. A Cognitive Approach to Adverbial Subordination in European Portuguese. The infinitive, the clitic pronoun Se and finite verb forms. Cambridge: Cambridge Scholars Publishing.

Vieira da Silva, Maria Cristina. 2003. A complementação infinitiva em textos latinos dos séculos XI e XII e textos portugueses dos séculos XIII e XIV. Reflexões sobre o Latim-Romance e o Português Antigo. Dissertação de Doutoramento. Universidade Nova de Lisboa. 